\title{
HUBUNGAN ANTARA TINGKAT KECERDASAN SPIRITUAL DENGAN TINGKAT STRES PADA MAHASISWA PSIKOLOGI YANG MENYUSUN SKRIPSI DI UNIVERSITAS HALU OLEO TAHUN AKADEMIK 2018/2019
}

\author{
Muhammad Asrun ${ }^{1}$, Aspin ${ }^{2}$, \& Dodi Priyatmo Silondae ${ }^{3}$ \\ Program Studi Psikologi \\ Fakultas Keguruan dan Ilmu Pendidikan, Universitas Halu Oleo \\ Email : asrunmds02@gmail.com
}

\begin{abstract}
ABSTRAK
Tujuan penelitian ini adalah untuk mengetahui hubungan antara tingkat kecerdasan spiritual dengan tingkat stres pada mahasiswa psikologi yang menyusun skripsi pada FKIP UHO. Penelitian ini dilaksanakan pada semester genap tahun ajaran 2018/2019, di jurusan Psikologi Universitas Halu Oleo pada mahasiswa psikologi angkatan 2015 yang berjumlah 43 orang. Jenis penelitian ini berupa penelitian kuantitatif korelasional. Hasil penelitian menunjukkan bahwa mahasiswa psikologi Universitas Halu Oleo memiliki tingkat stres yang mayoritas masuk dalam kategori sedang. Tingkat stres tinggi dalam menyusun skripsi berjumlah 7 subjek atau $18,6 \%, 30$ subjek masuk pada kategori sedang dengan persentase sebesar $62,7 \%$ dan sisanya sebanyak 6 subjek masuk dalam kategori rendah dengan persentase sebesar $13,95 \%$. Untuk tingkat kecerdasan spiritual mayoritas mahasiswa psikologi memiliki kecerdasan spiritual yang masuk dalam kategori sedang. Hasil menunjukkan bahwa 8 subjek atau dengan persentase 18,6\% masuk dalam kategori tinggi,27 subjek masuk pada kategori sedang dengan persentase $62,7 \%$ dan sisanya sebanyak 8 subjek masuk dalam kategori rendah dengan persentase sebanyak $18,6 \%$. Hasil korelasi menunjukkan ada hubungan negatif antara tingkat kecerdasan spiritual dengan tingkat stres dalam menyusun skripsi. Sehingga Ha pada penelitian ini diterima dengan kesimpulan ada hubungan antara tingkat kecerdasan spiritual dengan tingkat stres pada mahasiswa psikologi yang menyusun skripsi di Universitas Halu Oleo.
\end{abstract}

Kata Kunci : Kecerdasan Spiritual, stres, mahasiswa psikologi

\begin{abstract}
This study aims to determine the relationship between the level of spiritual intelligence with the level of stress in psychology students who compile theses at FKIP UHO. This research was conducted in the even semester of academic year 2018/2019 at Department of Psychology of Halu Oleo University especially in psychology class of 2015. The participants were 43 students. Correlational quantitative study was used in this research. The results showed that the psychology students had the majority of stress levels in the medium category. High stress level in preparing thesis amounted to 7 subjects or 18,6\%, 30 subjects were included in the moderate category with percentage of $62,7 \%$ and the remaining 6 subjects were included in the low category with percentage of $13,95 \%$. Level of spiritual intelligence of majority psychology students was included in the medium category. The results showed that 8 subjects or with percentage of $18,6 \%$ included in the high category, 27 subjects included in the moderate category with percentage of $62,7 \%$ and the rest 8 subjects were included in the low category with percentage of $18,6 \%$. The results of the correlation showed there was a negative relationship between level of spiritual intelligence and stress levels in preparing thesis. Thus, Ha in this study was accepted with the conclusion that there was a relationship between the level of spiritual intelligence and stress level in psychology students who preparing theses at Halu Oleo University.
\end{abstract}

Keywords : Spiritual intelligence, stress, psychologi students 


\section{Pendahuluan}

Mahasiswa tingkat akhir adalah mahasiswa yang sedang dalam proses mengerjakan skripsi sebagai syarat kelulusan sehingga wajib dikerjakan bagi mahasiswa yang ingin menyelesaikan studi dan mendapatkan gelar sarjana. Mahasiswa tingkat akhir dituntut untuk membuat sebuah karya ilmiah dari hasil penelitian yang dilakukan dan diharapkan dapat bermanfaat bagi masyarakat secara umum.

Proses penyusunan skripsi dilakukan secara individual oleh setiap mahasiswa. Hal tersebut dimaksudkan agar mahasiswa dapat mandiri dalam pemecahan masalah terhadap penelitian yang dilakukan. Namun tidak sedikit mahasiswa dalam proses penyusunannya mengalami kesulitan.

Sejalan dengan temuan di lapangan, beberapa mahasiswa kesulitan dalam menyusun skripsi dimulai dari pemilihan judul yang relatif lama dan membutuhkan banyak pertimbangan tentang judul yang dipilih, pemilihan metode penelitian yang sesuai dengan judul penelitian dan realitas lingkungan yang diteliti (Wawancara, 21 Februari 2019).

$$
\text { Berbagai kesulitan seperti }
$$
dijelaskan sebelumnya berpotensi menyebabkan tekanan pada diri mahasiswa. Semakin kompleks aktivitas yang berkaitan dengan skripsi, semakin tinggi tingkat kesulitan mahasiswa dalam mengerjakan skripsi. Fenomena ini dapat berimplikasi pada munculnya macammacam reaksi mahasiswa terhadap tugas akhir, salah satu reaksi yang sering diderita oleh mahasiswa pada umumnya adalah gangguan stres.

Menurut Sarafino (Gintulangi \& Prihastuti, 2014) bahwa stres pada mahasiswa dalam mengerjakan skripsi merupakan keadaan yang disebabkan oleh interaksi antara individu dengan lingkungan yang menimbulkan adanya persepsi terhadap tuntutan dari sebuah situasi yang kemudian berdampak pada sistem biologis, psikologis dan sosial pada diri seseorang
Stres yang dialami mahasiswa yang mengerjakan skripsi, umumnya bersifat negatif, sebab stres tersebut menimbulkan kerugian pada diri mahasiswa.

Stres dalam hal penyusunan skripsi juga dialami oleh mahasiswa Jurusan Psikologi Fakultas Keguruan dan Ilmu Pendidikan (FKIP) Universitas Halu Oleo (UHO). Berdasarkan hasil wawancara terhadap 10 orang mahasiswa, ditemukan delapan mahasiswa yang terindikasi mengalami stres dalam menyusun skripsi mereka. Gejala fisiologis yang sering mereka rasakan adalah sakit kepala, susah untuk memulai tidur, gangguan makan, serta gangguan kulit. Adapun gejala psikologis yang dirasakan adalah menurunnya daya ingat, perhatian yang tidak fokus, mudah marah, kecemasan yang berlebihan, merasa sedih serta sering bermasalah dalam hubungan interpersonal.

Keadaan tersebut pada dasarnya disebabkan karena adanya tuntutan yang mereka hadapi serta keinginan dari pihak orang tua agar segera lulus dan mencari pekerjaan yang sesuai, teman sebaya yang telah lulus dan mulai bekerja, dunia kerja yang menawarkan peluang serta kebutuhan untuk mengaktualisasikan diri yang semakin besar. Keadaan inilah yang cenderung menambah rasa tertekan dan rasa stres yang mereka alami. Peristiwa ini sejalan dengan hasil penelitian yang dilakukan oleh Pangestuti (Fauziah, 2014), menjelaskan bahwa mahasiswa yang sedang menyusun skripsi dan melakukan penundaan penyelesaian skripsi mengalami peningkatan stres yang cukup tinggi.

Stres yang melebihi tahap tertentu akan menimbulkan berbagai masalah bagi mahasiswa apabila tidak dikelola dengan sebaik-baiknya. Pada tingkat stres yang berat, seseorang bisa menjadi depresi, kehilangan percaya diri dan harga diri (Ferawati \& Amiyakun, 2015). Namun, melalui pengolahan stresor yang tepat dengan strategi koping adaptif, stres dapat berdampak positif. Faktor yang berperan dalam strategi koping, satu di antaranya 
adalah kecerdasan spiritual (Aswandi, 2017).

Kecerdasan spiritual pada dasarnya digunakan sebagai kerangka dasar dalam bertindak (Wahab \& Umiarso, 2010). Individu (mahasiswa) yang tidak memiliki kecerdasan spiritual yang baik, dapat menyebabkan kesulitan dalam hal mengendalikan diri, tidak mampu mengenal dirinya sendiri, dan sulit memotivasi diri (Pourfarokh, 2014). Sebaliknya mahasiswa yang memiliki kecerdasan spiritual yang tinggi akan mampu memikirkan setiap kemungkinan akibat dari tindakan-tindakannya sehingga ia akan menghindari tindakan-tindakan yang dapat merugikan dirinya sendiri maupun orang lain (Liling, 2013).

Berdasarkan latar belakang tersebut peneliti tertarik untuk melakukan penelitian yang berjudul "Hubungan Antara Tingkat Kecerdasan Spiritual Dengan Tingkat Stres Pada Mahasiswa Psikologi yang Menyusun Skripsi di Universitas Halu Oleo Tahun Akademik 2018/2019" dimana penelitian ini di lakukan pada mahasiswa Jurusan Psikologi FKIP UHO dengan tujuan untuk melihat tingkat stres khususnya stres menyusun skripsi dengan tingkat kecerdasan spiritual yang berbeda pada setiap mahasiswa.

\section{Rumusan Masalah}

Rumusan masalah dalam penelitian ini yaitu :

1. Bagaimana tingkat stres pada mahasiswa psikologi yang menyusun skripsi pada FKIP UHO?

2. Bagaimana tingkat kecerdasan spiritual pada mahasiswa psikologi FKIP UHO yang menyusun skripsi?

3. Apakah ada hubungan antara tingkat kecerdasan spiritual dengan tingkat stres pada mahasiswa psikologi yang menyusun skripsi pada FKIP UHO?

\section{Tujuan Penelitian}

Tujuan dari penelitian ini ialah untuk :

1. Mengetahui tingkat stres pada mahasiswa psikologi yang menyusun skripsi pada FKIP UHO.

2. Mengetahui tingkat kecerdasan spiritual dengan tingkat stres pada mahasiswa psikologi yang menyusun skripsi pada FKIP UHO.

3. Mengetahui hubungan antara tingkat kecerdasan spiritual dengan tingkat stres pada mahasiswa psikologi yang menyusun skripsi pada FKIP UHO.

\section{Manfaat Penelitian}

Hasil dari penelitian ini diharapkan dapat bermanfaat, adapun manfaatnya sebagai berikut:

1. Manfaat Praktis

a. Penelitian ini dapat dimanfaatkan bagi mahasiswa dalam menemukan suatu solusi terkait penanganan stres dalam menyusun skripsi dengan memanfaatkan kecerdasan spiritual sebagai alternatif baru dalam penanganannya.

b. Dapat dimanfaatkan oleh penasehat akademik dan dosen pembimbing kepada setiap mahasiswa dalam memberikan masukan terkait penanganan stres dalam menyusun skripsi serta dalam hal mengerjakan tugas-tugas lainnya yang berkaitan dengan tugas akademik.

2. Manfaat Teoritis

a. Penelitian ini di harapkan dapat menambah khazanah ilmu pengetahuan.

b. Dapat digunakan sebagai bahan referensi terkait penelitian yang mengukur kecerdasan spiritual maupun stres dalam menyusun skripsi.

\section{Metode Penelitian \\ Bentuk Penelitian}

Bentuk penelitian yang dilakukan dalam penelitian ini yaitu penelitian kuantitatif yakni suatu proses menemukan 
pengetahuan yang menggunakan data berupa angka sebagai alat untuk menganalisis keterangan mengenai apa yang ingin diketahui (Kasiram, 2010).

\section{Populasi dan Sampel Penelitian}

Populasi dalam penelitian ini adalah mahasiswa jurusan psikologi FKIP UHO angkatan 2015 yang berjumlah 46 orang dan sedang dalam proses menyusun skripsi. Adapun sampel dalam penelitian ini berjumlah 43 orang dengan menggunakan teknik total sampling.

\section{Definisi Operasional}

\section{Kecerdasan Spiritual}

Kecerdasan spiritual adalah keadaan mahasiswa dalam menerima dan menghadapi skripsi sebagai tolak ukur keberhasilan mahasiswa pada semester akhir. Dalam mengukur tingkat kecerdasan spiritual mahasiswa, peneliti menggunakan indikator kecerdasan spiritual menurut King dan DeCicco (2009) yang terdiri dari dimensi critical existential thinking, personal meaning production, transcendent awareness, dan conscious state expansion sebagai instrumen penelitian.

\section{Stres dalam menyusun skripsi}

Stres dalam menyusun skripsi didefinisikan sebagai keadaan dalam diri mahasiswa yang merasa tertekan dan tidak mampu menyeimbangkan antara tuntutan dan kemampuan dalam menyelesaikan tugasnya. Dalam mengukur tingkat stres mahasiswa dalam menyusun skripsi, peneliti menggunakan indikator stres menurut Sarafino dan Smith (2011) yang terdiri dari dimensi biologis dan psikologis sebagai instrumen penelitian.

\section{Analisis Data}

\section{Analisis Deskripsi \\ Mencari Mean}

Mean adalah pengertian rata-rata matematik yang harus dihitung dengan cara tertentu dan dapat sebagai jumlah semua angka dibagi oleh banyaknya yang dijumlahkan (Hadi, 2015).

\section{Mencari standart deviasi}

Standar deviasi adalah akar dari jumlah deviasi kuadrat dibagi banyaknya individu dalam distribusi (Hadi, 2015).

\section{Mencari Presentase}

Presentase yaitu data yang menggunakan teknik analisa statistik prosentase (Hadi, 2015). Setelah dilakukan perhitungan standar deviasi berdasarkan norma diatas dan didapatkan frekuensi setiap kategori.

\section{Analisis Inferensial Uji Normalitas}

Pedoman yang digunakan untuk normal tidaknya sebaran adalah jika $\mathrm{p}>$ 0.05 maka data dikatakan normal, sedangkan apabila $\mathrm{p}<0.05$ maka data dikatakan tidak normal.

\section{Uji Linearitas}

Uji linearitas bertujuan untuk mengetahui apakah dua variabel mempunyai hubungan yang linear atau tidak secara signifikan. Analisis ini menggunakan SPSS dengan Test for Linearity yang mempunyai taraf signifikan 0.05 .

\section{Analisis Korelasi}

Uji korelasi yang digunakan dalam penelitian ini yaitu menggunakan korelasi Product Moment, jika data yang dihasilkan bersifat normal.Sedangkan, apabila data yang dihasilkan tidak masuk dalam kategori normal, maka uji korelasi yang digunakan adalah Uji korelasi Kendall's Tau-b dengan bantuan program SPSS 20.0 .

\section{Hasil Penelitian dan Pembahasan Hasil Penelitian}

Hasil penelitian menunjukkan bahwa tingkat kecerdasan spiritual mahasiswa psikologi FKIP UHO mayoritas berada pada tingkat sedang, dengan nilai 
persentase sebesar $62,7 \%$, dimana hal tersebut dapat diartikan bahwa mahasiswa psikologi memiliki tingkat kecerdasan spiritual yang cukup baik, sedangkan tingkat stres mahasiswa psikologi yang menyusun skripsi pada FKIP UHO mayoritas berada pada tingkat sedang, dengan nilai persentase sebesar 69,76\% yang dapat diartikan bahwa mahasiswa psikologi cenderung memiliki tingkat stres yang cukup tinggi dan pada dasarnya dipengaruhi oleh adanya faktor internal maupun eksternal. Faktor internal mahaiswa dipengaruhi karena adanya ketidakmampuan mahasiswa dalam mengelola tekanan yang diadapati ketika mendapat masalah dalam proses menyususn skripsi, sedangkan faktor ekstrenal dipengaruhi oleh kurangnya literatur dalam menyusun skripsi.

Adapun kriteria hubungan keterkaitan antara kedua variabel setelah dilakukan analis dan pengujian menunjukkan hasil ada hubungan yang signifikan antara tingkat kecerdasan spiritual dengan tingkat stres pada mahasiswa psikologi yang menyusun skripsi yang ditunjukkan dengan nilai $r$ sebesar-0,514>0,05.

\section{Pembahasan}

Berdasarkan hasil yang diperoleh dalam penelitian ini, menunjukkan bahwa tingkat kecerdasan spiritual mahasiswa psikologi mayoritas berada pada kategori sedang yakni $62,7 \%$. Hal ini ditandai dengan adanya beberapa contoh strategi koping adaptif yang terjadi di lapangan pada sebagian besar mahasiswa psikologi dalam proses penyusunan skripsi, yakni mereka memiliki sifat tawakal dan berserah diri kepada Allah SWT terhadap segala cobaan yang menimpa mereka, kerendahan hati dengan selalu menerima nasehat dari orang lain, serta rasa optimisme mereka yang tetap berusaha mencari solusi dari beberapa persoalan yang mereka hadapi dengan mempertimbangkan berbagai kondisi yang terjadi di lapangan.
Keadaan tersebut pada umumnya terjadi pada diri mahasiswa psikologi ketika mendapat banyak persoalan yang sulit untuk mereka selesaikan dalam proses penyusunan skripsi. Contoh-contoh kesulitan yang mereka sering alami saat mengerjakan skripsi adalah pemilihan metode penelitian yang harus sesuai dengan judul penelitian dan realitas lingkungan yang diteliti, pencarian bahan literatur yang relatif lama dan sulit didapatkan, proses mengkomunikasikan dan mempertahankan gagasan pemikiran dengan dosen pembimbing yang tidak mudah dan revisi proposal penelitian yang dilakukan hinga berulang-rulang kali.

Jika ditinjau dari sudut pandang tingkat stres dalam menyusun skripsi, mayoritas mahasiswa psikologi tergolong memiliki tingkat stres yang tergolong dalam kategori sedang dengan persentase $69,76 \%$. Ciri-ciri mahasiswa psikologi yang memiliki tingkat stres dalam kategori sedang ketika melakukan proses penyusunan skripsi adalah mereka cenderung mengalami stres dengan jangka waktu beberapa jam sampai dengan beberapa hari yang pada dasarnya dipengaruhi oleh sebab kerja yang berlebih dan ketidak mampuan dalam menyelesaikan pekerjaan tersebut sesuai dengan target waktu yang ditentukan. Peristiwa tersebut sejalan dengan yang dinyatakan oleh Rasmund (Mahmud \& Uyun 2016) yang berpendapat bahwa masalah kerja yang dihadapi seseorang tanpa adanya penyelesaian yang tepat akan menimbulkan stres.

Adapun hubungan antara tingkat kecerdasan spiritual dengan tingkat stres pada mahasiswa psikologi yang menyusun skripsi pada FKIP UHO berdasarkan hasil pengujian menunjukkan ada hubungan yang signifikan antara kedua variabel. Dimana diperoleh harga koefisien korelasi sebesar -0,514.

Jika merujuk pada hasil kesimpulan yang didapat bahwasanya mahasiswa psikologi memiliki tingkat stres dan kecerdasan spiritual yang mayoritas 
tergolong dalam kategori sedang, hal ini dapat diartikan bahwa mahasiswa psikologi dalam proses penyusunan skripsi masih cenderung mengalami stres dengan adanya kesulitan yang didapati dalam proses penyusunannya, namun keadaan tersebut bisa dinetralisir dengan adanya kecerdasan spiritual yang dimiliki dengan karakteristik sifat tawakal dan berserah diri kepada Allah SWT ketika mendapat cobaan-coban tersebut dalam proses penyusunannya.

Maka hipotesis ada hubungan antara tingkat kecerdasan spiritual dengan tingkat stres pada mahasiswa yang menyusun skripsi diterima, adapun hasil pengujiannnya sebagai berikut:

Tabel 1. Hasil uji hipotesis

\begin{tabular}{ccc}
\hline Variabel & $\boldsymbol{R} \boldsymbol{x y}$ & Keterangan \\
\hline $\begin{array}{c}\text { Stres dalam } \\
\text { menyusun skripsi }\end{array}$ & $-0,514$ & Signifikan \\
\hline Kecerdasan spiritual & $-0,514$ & Signifikan
\end{tabular}

Berdasarkan harga koefisien korelasi yang bertanda negatif, ini berarti menunjukkan adanya arah hubungan yang berlawanan. Artinya semakin tinggi tingkat kecerdasan spiritual maka akan dibarengi dengan semakin rendahnya tingkat stres pada mahasiswa psikologi yang menyusun skripsi di UHO.

\section{Kesimpulan dan Saran Kesimpulan}

Berdasarkan hasil penelitian yang dilakukan dapat disimpulkan bahwa:

1. Tingkat kecerdasan spiritual mahasiswa psikologi FKIP UHO mayoritas berada pada tingkat sedang, dengan nilai persentase sebesar $62,7 \%$, dimana hal tersebut dapat diartikan bahwa mahasiswa psikologi memiliki tingkat kecerdasan spiritual yang cukup baik.

2. Tingkat stres mahasiswa psikologi yang menyusun skripsi pada FKIP
UHO mayoritas berada pada tingkat sedang, dengan nilai persentase sebesar $69,76 \%$ yang dapat diartikan bahwa mahasiswa psikologi cenderung memiliki tingkat stres yang cukup tinggi dan pada dasarnya dipengaruhi oleh adanya faktor internal maupun eksternal.

3. Terdapat hubungan yang signifikan antara tingkat kecerdasan spiritual dengan tingkat stres pada mahasiswa psikologi yang menyusun skripsi yang ditunjukkan dengan nilai $\mathrm{r}$ sebesar $0,514>0,05$.

\section{Saran}

Berdasarkan hasil penelitian yang diperoleh dalam penelitian ini maka, peneliti memberikan saran antara lain:

1. Bagi mahasiswa psikologi

a. Diharapkan kedepannya agar setiap mahasiswa psikologi terus memperkaya diri dan menerapkan ilmu yang telah diperoleh sebagaimana pada umumnya sehingga, ketika mendapat tekanantekanan yang bersifat negatif baik itu yang arahnya internal maupun eksternal terkait tugas akhir, mampu diatasi tanpa ada ketertekanan dan rasa frustasi yang bisa menimbulkan stres.

b. Kecerdasan spiritual merupakan sebuah kecerdasan yang jika dikaji lebih dalam bisa menjadi strategi koping yang paling efektif dalam hal penanganan stres, oleh karena itu alangkah baiknya kedepan agar setiap mahasiswa psikologi mampu untuk mengasah kecerdasan spiritualnya dengan banyak mengkaji ilmu serta mengikuti organisasi-organisasi yang berbasis agama yang bisa memberikan kemaslahatan bagi dirinya dan orang-orang di sekitarnya.

2. Bagi penelitian selanjutnya

a. Berdasarkan keterbatasan penelitian yang telah dijelaskan sebelumnya, diharapkan untuk 
penelitian selanjutnya agar dapat memperbanyak subjek yang akan diteliti. Hal tersebut bertujuan agar data yang diperoleh memiliki persebaran yang merata, sehingga dapat semakin menggambarkan populasi yang ada.

b. Penelitian selanjutnya disarankan agar menggunakan sampel yang tersebar dari beberapa jurusan agar hasil yang diperoleh bisa mewakili karateristik dari atribut yang hendak diukur.

\section{Daftar Pustaka}

Aswandi, F. (2017). Hubungan Kecerdasan Spiritual dengan Tingkat Stres pada Mahasiswa Keperawatan Universitas Tanjung Pura Pontianak. Skripsi. Fakultas Kedokteran Universitas Tanjungpura Pontianak, Pontianak.

Fauziah, N. (2014). Empati, Persahabatan, dan Kecerdasan Adversitas pada mahasiswa yang Sedang Skripsi. Jurnal Psikologi, Vol.13, no.1, 7892.

Ferawati \& Amiyakun, S. (2015). Pengaruh Pemberian Terapi Musik Terhadap Penurunan Kecemasan dan Tingkat Stres Mahasiswa Semester VII Ilmu Keperawatan dalam Menghadapi Skripsi di Sekolah Tinggi Ilmu Kesehatan Insan Cendekia Husada Bojonegor. Jumakia. 2015, Vol. 1, no. 1, 1-9.

Gintulangi, I., \& Prihastuti. (2014). Hubungan Persepsi Mahasiswa Terhadap Harapan Orang tua dalam Penyelesaian Studi S1 dengan Tingkat Stress Mahasiswa dalam Mengerjakan Skripsi. Jurnal Psikologi Klinis Dan Kesehatan mental, 3. 134-139.

Hadi, S. (2015). Statistik. Yogyakarta. Penerbit: Pustaka Pelajar
King, D. B., \& DeCicco, T. L. (2009) . A Viable Model and Self-Report Measure of Spiritual Intelligence. Canada: Trent University, 28(1).

Liling, E., R. (2013). Hubungan Antara Kecerdasan Spiritual dengan Prokrastinasi pada Mahasiswa Tingkat Akhir, 10(2), 59-72

Mahmud, R., \& Uyun, Z. (2016). Studi Deskriptif Mengenai Pola Stres pada Mahasiswa Praktikum. Jurnal Indigeneous, Vol 1, 52-61.

Pourfarokh. (2014). Studi Of The Relationship Between Spiritual Intelligence and Self Esteem With Ways Of Stress Coping Styles In University Student. International Conference On Social Sciences and Humanities, 8-10.

Sarafino, E.P., \& Smith, T.W. (2011). Health Psyhology:Biopsycholosoci al Interaction. John Wiley \& Sons Inc.

Wahab, A. \& Umiarso. (2010). Kepemimpinan Pendidikan dan Kecerdasan Spiritual. Jogjakarta: Ar Ruzmedia. 